Jaurnal of Enviranmental Science, Computer Science and Engineering \& Technology

An International Peer Review E-3 Journal of Sciences and Technology

\author{
Available online at www.jecet.org
}

Section B: Computer Science

Research Note

\title{
Business process management (BPM) challenges in digital transformation initiatives
}

\author{
Abdulrahman Almutawa and Prof. Majed Al-mashari \\ King Saud University, College of Computer and Information Sciences, Riyadh, \\ Saudi Arabia
}

Received: 18 April 2020; Revised: 15 May 2020; Accepted: 21 May 2020

\begin{abstract}
Digital transformation currently is a major focus area in industries. It is a combination of technology, process, and people that supports the ability to operate as a digital business. Business process management plays a major role in the success of digital transformation initiatives. In this article, the concepts of digitization, digitalization, digital transformation, and Business process management (BPM) are discussed. Finally, the challenges of BPM in digital transformation are identified.
\end{abstract}

Keyword: Digital transformation, Digitization, challenges

\section{INTRODUCTION}

Digital transformation has been researched in many articles and journals ${ }^{[1-5]}$. Digital transformation provides a valuable opportunity for business processes to switch from the manual process to be an automated process. The importance of digital transformation is to increase the revenue and improve the process towards achieving the business strategy and goals. In this article, digitization, digitalization, and digital transformation concepts are discussed in section 1 to show their differences. Moreover, Business process management definition and challenges in digital transformation initiatives which are categorized as technology challenges, management challenges, and personal challenges are discussed in section 2 . 


\section{LITERATURE REVIEW}

In the business world, digital transformation plays a major role in business improvement and success. Consultants, managers, and researchers are working to improve and apply digital transformation initiatives to gain its benefits. Digitization and digitalization are two terms that are closely associated, but both have different concepts. According to Bloomberg, Jason ${ }^{[6]}$, Digitization is the process of changing from analogy to digital form. There are many examples of digitization such as converting handwritten text to digital. On the other hand, Digitalization is defined as the way many domains of human life are restructured with digital communication and media infrastructures ${ }^{[7]}$. Consequently, digital transformation relates to digitalization where organizations use digital initiatives to enhance their business process and deliver rich values to the customers ${ }^{[8]}$. Although digital transformation definition is discussed in many articles, it does not describe the concept from all aspects. The authors Fitzgerald, Michael et $a l .{ }^{[8]}$ established a pattern to evaluate the comprehensiveness of the current definitions. The pattern is as follows:

\section{“... Something with certain characteristics; that is driven by something; to create certain impacts;} on certain aspects of the organization"

The following table shows the results of the evaluation:

\begin{tabular}{|c|c|c|c|}
\hline Source & $\begin{array}{l}\text { Organizational } \\
\text { strategy formulated } \\
\text { and executed by } \\
\text { leveraging digital } \\
\text { resources to create } \\
\text { differential value }^{[9]}\end{array}$ & $\begin{array}{l}\text { The use of technology } \\
\text { to improve } \\
\text { performance or reach } \\
\text { of enterprises }\end{array}$ & $\begin{array}{l}\text { Digital transformation is } \\
\text { concerned with the rapid } \\
\text { changes of digital } \\
\text { technologies that can bring } \\
\text { about in a company's } \\
\text { business model, which } \\
\text { result in changed products } \\
\text { or organizational } \\
\text { structures or in the } \\
\text { automation of processes }\end{array}$ \\
\hline ...is something... & Strategy & $? ? ?$ & ??? \\
\hline $\begin{array}{l}\text {...with certain } \\
\text { characteristics ... }\end{array}$ & $? ? ?$ & Radically & Change \\
\hline $\begin{array}{l}\text {...that is driven by } \\
\text { something... }\end{array}$ & $\begin{array}{lr}\text { formulated } & \text { by } \\
\text { leveraging } & \text { digital } \\
\text { resources } & \end{array}$ & Technology & Digital technologies \\
\hline $\begin{array}{l}\text {...to create certain } \\
\text { impacts... }\end{array}$ & $\begin{array}{c}\text { to create differential } \\
\text { value }\end{array}$ & Improve performance & Automation \\
\hline $\begin{array}{l}\text {...on certain aspects } \\
\text { of the organization }\end{array}$ & Organization wide & Enterprise wide & $\begin{array}{l}\text { Business model; Products; } \\
\text { Organizational structures; } \\
\text { Processes }\end{array}$ \\
\hline
\end{tabular}

As shown, the inconsistencies of each current definition are illustrated. The authors work upon this table to construct a general digital transformation definition. After describing the characteristics, drivers, and impacts of digital transformation, the authors proposed the following definition:

“An evolutionary process that leverages digital capabilities and technologies to enable business models, operational processes and customer experiences to create value” 
According to the digital transformation expert in the large oil production company, digital transformation can be defined as the following:

"Digital transformation is the profound transformation of business and organizational activities, processes, competencies and models to fully leverage the changes and opportunities of a mix of digital technologies and their accelerating impact across society in a strategic and prioritized way, with present and future shifts in mind"

Digital transformation has many benefits on organizations. According to the IDC report, digital transformation could worth around $\$ 18$ trillion in additional business value. While research firm Gartner's CIO Agenda suggests digital business will represent an average of $36 \%$ of a business's revenue by 2020. Gartner predicts that by 2020 , more than 30 billion devices will be connected to the Internet (IoT). Digital businesses need the following major platforms to transform:

- Information systems platform.

- Customer experience platform.

- Data and analytics platform.

- IoT platform.

- Ecosystems platform.

\section{WHAT IS BPM?}

According to Gartner ${ }^{[12]}$, Business process management (BPM) is defined as the following:

"A discipline that uses various methods to discover, model, analyze, measure, improve and optimize business processes. A business process coordinates the behavior of people, systems, information, and things to produce business outcomes in support of a business strategy. Processes can be structured and repeatable, or unstructured and variable. Though not required, technologies are often used with BPM. BPM is key to align IT/OT investments to business strategy”.

BPM uses technology and management methods to optimize business processes. Technology has crucial importance in generating value and improving customers' experience who are involved in the business ${ }^{[13]}$.

Moreover, BPM also concerned with the management process which could significantly impact the improvement of the business processes. Business process management (BPM) can be described as a holistic view of organizational management practice, which requires top management support and involvement. Moreover, BPM focus on the alignment of key business processes and their enabling elements toward the business goals, strategy, and policies of an organization ${ }^{[14]}$.

Other article defines Business process management (BPM) as a field of management that can be defined as a paradigm that includes methods, techniques, and tools to support the design, enactment, management, and analysis of operational business processes ${ }^{[15]}$.

It is obviously noted that Business process management (BPM) and digital transformation definitions are sharing some characteristics. Although BPM is more general and covers many aspects such as management, business processes, and technology to achieve certain goals, it interests in improving and utilizing the digital technologies to improve the business process and achieve the organizational goals and strategy. 


\section{DIGITAL TRANSFORMATION INITIATIVES}

There are many DT initiatives utilized in industries and organizations. However, it is difficult to discuss and evaluate all DT initiative to identify their challenges. Therefore, in this paper, an interview was conducted with a digital transformation expert in oil and gas companies to identify a list of possible initiatives that can be utilized to enhance the business process. 3 initiatives are discussed in this paper to show their impacts on improving the business process and customer experience.

The first initiative is the Pipeline line-up process automation: this initiative aims to automate the control of the valve system. The valve system is used in the pipeline process to control the flow of oil and gas. It is used to be completely manual by having a human intervention to control the valve system. This initiative aims to utilize the power of digital technology (robotics) to operate this process which in turn reduces the efforts of man-powers and cost. The second initiative is the project tracking system. Tracking the project progress systematically is one of the success factors of project completion.

This initiative mainly focuses on tracking the project statistics, generates KPIs, and visualizes the reports to the concerned parties. This initiative aims to replace the manual process of having a single entity collects the data and generate the reports. It would increase the performance of tracking the projects' progress to ensure their completion and success. The last initiative is Auto Ops Handheld Checklist. This initiative aims to automate the daily task of inspecting the hauling trucks in the oil and gas companies. Inspection needs to check specific aspects of each equipment. Thus, utilizing handheld devices to verify the truck's compliance would improve the process significantly. Handheld devices use the RFID technology to read the tags associated with each truck to verify and display the full history of each piece of equipment.

\section{RESULTS AND DISCUSSION}

This article describes our findings from interview inputs from 3 entities in oil and gas companies that were involved in digital transformation journeys. We identified the BPM challenges that affect the applying of digital transformation initiatives. These challenges are summarized as the following:

Technology challenges: These challenges are related to the applicability of utilizing the DT technology in the business process. Some of the DT technologies are not applicable to be implemented on a single entity due to the technical restriction and the nature of the business environment. For example, the Pipeline line-up process automation initiative is only applicable in the pipeline business which mainly deals with the pipeline operation. Moreover, enabling this technology initiative requires considering other business requirements such as safety and reliability.

Management challenges: These challenges are related to management support and policies. Top management support plays a major role in enabling the DT technologies in a certain business entity. According to inputs received from the interview, management challenges could lack top management support, top management focuses on the operation perspectives rather than technologies perspectives, cost, and other internal policies restrictions. All these management obstacles may affect the implementation of the DT program and initiatives in business.

Personal challenges: These challenges are related to the attitudes of the people and their interests in digital transformation initiatives. Enthusiastic of the people play effective roles towards the successful 
implementation of any new initiatives. Moreover, people need training and awareness programs to deal with new DT initiatives.

All these above-mentioned challenges are concerning aspects of Business process management which focus on the behavior of the people and other factors toward achieving business strategy and goals.

\section{CONCLUSION}

In this article, we discussed the concepts of digitization, digitalization, and digital transformation. Digitization is defined as the process of converting analog data to digital whereas digitalization is defined as the way many domains of social life are restructured around digital communication and media infrastructures, and digital transformation relates to utilizing digital initiatives to enhance business process and deliver rich values to the customers. Moreover, Business process management (BPM) is defined as a discipline that uses various methods to discover, model, analyze, measure, improve, and optimize business processes. After that, an interview was conducted with DT experts in large oil and gas companies to identify the challenges of Business process management (BPM) in digital transformation initiatives, and these challenges are classified into 3 categories: Technology challenges, Management challenges, and Personal challenges.

\section{ACKNOWLEDGMENTS}

The authors would like to thank Deanship of scientific research in King Saud University for funding and supporting this research through the initiative of DSR Graduate Students Research Support (GSR)

\section{REFERENCES}

1. Berman, Saul J. "Digital transformation: opportunities to create new business models." Strategy \& Leadership 2012.

2. Sebastian, Ina, et al. "How big old companies navigate digital transformation." 2017.

3. Singh, Anna, and Thomas Hess. "How Chief Digital Officers promote the digital transformation of their companies." MIS Quarterly Executive, 2017, 16.

4. Andriole, Stephen J. "Five myths about digital transformation." MIT sloan management review 2017,58,3.

5. Horlach, Bettina, Paul Drews, and Ingrid Schirmer. "Bimodal IT: Business-IT alignment in the age of digital transformation." Multikonferenz Wirtschaftsinformatik (MKWI) (2016): 14171428.

6. Bloomberg, Jason. "Digitization, digitalization, and digital transformation: confuse them at your peril." Forbes. Retrieved on August, 2018, 28, 2019.

7. Brennen, J. Scott, and Daniel Kreiss. "Digitalization." The international encyclopedia of communication theory and philosophy, 2016, 1-11.

8. Fitzgerald, Michael, et al. "Embracing digital technology: A new strategic imperative." MIT sloan management review, 2014,55,2, 1 .

9. Bharadwaj, Anandhi, et al. "Digital business strategy: toward a next generation of insights." MIS quarterly, 2013, 471-482. 
10. Westerman, George, Didier Bonnet, and Andrew McAfee. "The nine elements of digital transformation." MIT Sloan Management Review, 2014, 55, 3, 1-6.

11. Hess, Thomas, et al. "Options for formulating a digital transformation strategy." MIS Quarterly Executive, 2016, 15, 2.

12. Gartner. "Business process management (BPM).

13. Møller, Charles, Carsten J. Maack, and Rune D. Tan. "What is business process management: A two stage literature review of an emerging field?" Research and practical issues of enterprise information systems II. Springer, Boston, MA, 2007, 19-31.

14. De Bruin, Tonia, and Michael Rosemann. "Towards a business process management maturity model." 2005, 1-12.

15. Meidan, Ayman, et al. "A survey on business processes management suites." Computer Standards \& Interfaces, 2017, 51, 71-86.

* Corresponding Author: Abdulrahman Almutawa,

King Saud University, College of Computer and Information Sciences, Riyadh, Saudi Arabia

Date of publication on line 21.05.2020 